\title{
Modulation of Transcriptional Activation of the Proliferating Cell Nuclear Antigen Promoter by the Adenovirus E1A 243- Residue Oncoprotein Depends on Proximal Activators
}

\author{
GILBERT F. MORRIS, † CLAUDE LABRIE, AND MICHAEL B. MATHEWS* \\ Cold Spring Harbor Laboratory, Cold Spring Harbor, New York 11724
}

Received 6 July 1993/Returned for modification 6 October 1993/Accepted 21 October 1993

\begin{abstract}
Previous analyses defined a proliferating cell nuclear antigen (PCNA) E1A-responsive element (PERE) in the PCNA promoter that is essential for transactivation by the 243-residue product of the adenovirus type 2 E1A 12S mRNA (E1A 243R). In this report, we show that the PERE activates a heterologous basal promoter and confers susceptibility to transactivation by E1A 243R, indicating that the PERE is both necessary and sufficient for the response of the PCNA promoter to this oncoprotein. Insertion of linker sequences between the PERE and the site of transcription initiation in the PCNA promoter severely impairs the promoter's response to E1A 243R transactivation. GALA sites can replace the function of the PERE in the E1A 243R response of the PCNA basal promoter if transcriptional activators of suitable strength are supplied as GALA fusion proteins. Weak transcriptional activators render the PCNA basal promoter subject to transactivation by E1A 243R but do not endow the adenovirus E1B basal promoter with a similar response. Strong transcriptional activators do not support transactivation by E1A 243R, however; instead, E1A reduces the ability of the strong activators to activate both the PCNA and E1B basal promoters. Although other mechanistic difierences might determine the response, the data imply a relationship between the activation strength of promoter-proximal efiectors and the response of the PCNA basal promoter to E1A 243R. These experiments indicate that the PERE can function autonomously in mediating transactivation by E1A 243R and that the PCNA basal promoter is configured in a manner that permits modulation by E1A 243R of transcriptional activation by promoter-proximal effectors.
\end{abstract}

Regulation of transcriptional initiation plays a critical role in gene expression (see references 11, 13, 89, and 94 for recent reviews). In eucaryotes, transcriptional initiation by RNA polymerase II is governed by the interplay between the general transcription factors and the transcriptional effectors. The general factors bind in close proximity to the site of transcription initiation to form an initiation complex that is nucleated by the binding of the TATA box-binding protein (TBP) and/or initiator protein $(9,10,64,70,77)$. The initiation complex specifies the site of transcriptional initiation of all genes transcribed by RNA polymerase II. The transcriptional effectors regulate transcription in a gene-specific manner via interactions with the basal machinery. The enhancerbinding proteins bind upstream or downstream from the basal promoter and regulate transcription in a distance- and orientation-independent manner $(18,37,52,60)$, whereas other regulatory factors that require a promoter proximal location for function bind immediately upstream from the basal promoter $(68,69)$. These promoter-proximal factors activate transcription or contribute to promoter activation by the enhancer-binding factors that bind distally $(69,82$, 91). Transcriptional adapters or coactivators augment the effect of the regulatory proteins on the initiation rate determined by the basal factors $(50,61,78)$.

The E1A gene of adenovirus encodes proteins that target the cellular transcriptional machinery as a means to mobilize the cell for the production of viral progeny $(22,57)$. By

* Corresponding author. Mailing address: Cold Spring Harbor Laboratory, P.O. Box 100, Cold Spring Harbor, NY 11724. Phone: (516) 367-8375. Fax: (516) 367-8815.

$\dagger$ Present address: Department of Pathology, Tulane University Medical Center, New Orleans, LA 70112. differential splicing of a single transcript, the E1A gene produces primarily the 289 - and 243 -residue E1A proteins (E1A 289R and E1A 243R) $(6,53)$. The 46 additional amino acids in the larger protein comprise a region with strong transcription activation properties that is conserved (conserved region 3) among adenoviruses of different serotypes $(6,22,53)$. The E1A 289R protein does not bind DNA sequence specifically (21); therefore, its transcriptional effects must be promulgated via protein-protein interactions $(42,45,87,89)$. Conserved region 3 of E1A 289R binds two regulatory proteins, the CCAAT box-binding factor (46) and activating transcription factor 2 (ATF-2) (45). Moreover, E1A 289R binds TBP $(33,42)$, an essential factor of the basal machinery, suggesting a mechanism for the promiscuous activation of transcription characteristic of E1A 289R (6, 22).

The small E1A protein (E1A 243R) of adenovirus fails to bind ATF- 2 and the CCAAT box-binding factor $(45,46)$ and binds less efficiently to TBP (42). Consequently, E1A 243R is less potent and more selective than E1A 289R in transcription activation (22). Nevertheless, it is likely that the transcriptional effects of E1A 243R relate more closely to the process of transformation, since either protein can cooperate with E1B to transform primary cells $(53,65,71)$. In general, E1A 243R represses transcription by inhibiting enhancer function $(63,80)$, a property that correlates with the ability of E1A 243R to bind a $300-\mathrm{kDa}$ cellular protein $(36,80)$. Despite this effect, E1A 243R can transactivate a variety of viral and cellular promoters $(43,56,74,86,96)$. One mechanism employed by E1A 243R to stimulate transcription involves the liberation of cellular factors from transcriptionally inactive complexes. Prominent among these is the dissociation of the cellular transcription factor E2F from complexes with 
the retinoblastoma susceptibility gene product, resulting in the activation of E2F-dependent transcription $(2,4)$. Furthermore, E1A 243R relieves transcriptional repression by YY1, a cellular regulatory factor that can also function basally as an initiator protein upon binding the transcription initiation site $(70,72)$.

The proliferating cell nuclear antigen (PCNA) is an essential DNA replication (59) and repair (74) protein that increases in abundance during periods of cell growth $(1,35$, 51). Both E1A 289R and E1A 243R can induce expression of PCNA during the transformation of primary rodent cells by adenovirus $(36,96)$. Although regulation of PCNA gene expression includes a posttranscriptional component (12), studies in HeLa cells indicate that E1A 243R can activate PCNA gene expression transcriptionally (55). Transactivation of the PCNA gene depends on multiple domains of E1A 243R (39) and on a PCNA E1A-responsive element (PERE) in the gene within the region from nucleotides -59 to -45 upstream of the transcriptional initiation site (41). The integrity of a sequence (nucleotides -52 to -45 ) with homology to an ATF/CRE motif within the PERE is critical for PERE recognition by nuclear proteins and for PERE-mediated transactivation of the PCNA promoter by E1A 243R $(41,55)$.

We have examined the role of the PERE in transactivation of the PCNA promoter by E1A 243R by using two complementary approaches. In the first instance, we introduced the PERE into a heterologous promoter that is not responsive to E1A 243R. The results show that the PERE is sufficient to mediate transactivation by E1A 243R. Conversely, we replaced the PCNA promoter's PERE with GAL4 binding sites and assayed the ability of various effectors expressed as GALA fusion proteins to substitute for the PERE-binding factors. In the absence of the PERE, the PCNA basal promoter displays little response to E1A 243R, but it responds to ElA transactivation in cooperation with weak activators. In contrast, activation of the PCNA basal promoter by strong transcriptional activators is repressed by E1A 243R. We suggest that the E1A 243R response of the PCNA promoter might be related to recruitment of the TFIID complex to a poorly recognized TATA motif in the PCNA promoter.

\section{MATERIALS AND METHODS}

E1A expression constructs. Plasmids that express E1A 243R (pCMV12S) or an E1A 243R mRNA with a reading frame alteration to prevent E1A 243R production (pCMV 12S.FS) were described previously (55).

Reporter constructs. Wild-type PCNA promoter constructs with $87(-87-+62$ PCNA-CAT) and 1265 nucleotides $(-1265-+62$ PCNA-CAT) of PCNA promoter sequence upstream of the transcription initiation site were described previously (54). The $\beta$-galactosidase reporter construct (pON260) was provided by Arne Stenlund and described previously (79). The CAT reporter construct with five GAL4 sites and the E1B TATA motif (G5BCAT) was obtained from K. Martin and M. Green (44).

To create G5P3BCAT, a double-stranded oligonucleotide corresponding to a $B g l I I$ restriction site was inserted into the $X b a I$ site of G5BCAT. A tandemly repeated sequence corresponding to three copies of nucleotides -59 to -45 of the PCNA promoter sequence (PERE [41]) with protruding 5' termini of GATC was then inserted into the newly created $B g l$ II site in the G5BCAT background.

Upstream PCNA promoter and vector sequences between the two Aat II sites in -1265-+62 PCNA-CAT were replaced by a $B g l I I$ linker to create BglPCNA-CAT, which contains PCNA promoter sequences from -47 to +62 relative to the transcription initiation site fused to the chloramphenicol acetyltransferase (CAT) reporter gene. Plasmid G5PCNACAT was prepared by linearizing BglPCNA-CAT with $B g l \mathrm{II}$, and a HindIII-Bam HI fragment from G5E4CAT (44) containing five GAL4 binding sites was inserted by adding $B g l \mathrm{II}$ linkers to the blunt HindIII site. Plasmids GC7PCNA-CAT and GC12PCNA-CAT were created by inserting a NcoIBamHI fragment corresponding to nucleotides 40 to 101 of the simian virus 40 (SV40) genome (95) with BamHI linkers into the $B g l$ II site of BglPCNA-CAT. The orientation of the SV40 fragment in GC7PCNA-CAT relative to the direction of transcription is the same as that of the late promoter in the viral genome (67). The inserted SV40 fragment contains six Sp1 binding sites, but the sequence of GC7PCNA-CAT revealed an additional Sp1 site with the sequence 5'-CGC CCCATG- $3^{\prime}$ at the distal end of the SV40 insert, for a total of seven such sites. The GC12PCNA-CAT plasmid contains two copies of the SV40 insert with the copy proximal to the PCNA promoter in the same orientation as GC7PCNA-CAT and the promoter-distal copy inverted (diagrammed in Fig. 3A).

Linker insertion mutants of $-87-+62$ PCNA-CAT were prepared by inserting multiple copies of linker DNA encoding an $\mathrm{XbaI}$ restriction site into BssHII-digested $-87-+62$ PCNA-CAT.

Efiector constructs. Plasmids that express GAL4-Sp1 [pSG4+Sp1N nucleotides encoding amino acids 83 to 621 of Spl fused in frame to a truncated GAL4 protein containing amino acids 1 to 147 GAL4(1-147)], GAL4-Sp1Q [pSG4+ Sp1Q nucleotides encoding amino acids 339 to 500 of Sp1 fused in frame to GAL4(1-147)], GAL4 region I (GAL4 REGI) (pSG246) (23), and the starting materials for preparation of mammalian expression vectors for GAL4(1-94) and GAL4 AH (amphipathic helix) were kindly provided by $\mathrm{G}$. Gill. Plasmids that express GAL4(1-147) (66) and GAL4 REGII (50) were provided by F. Liu and $K$. Martin in M. Green's laboratory.

A vector for expression of GAL4(1-94) in mammalian cells was prepared by subcloning a HindIII fragment from the yeast GALA(1-94) expression vector pGG17 (40) into the unique HindIII site in pECE (19). Similarly, a HindIII fragment from the yeast expression vector for GAL4 AH, pEG50 (25), was subcloned into $\mathrm{pECE}$ to make a mammalian expression vector for GAL4 AH.

Cell culture. Monolayer cultures of HeLa cells (ATCC CCL2) were grown under $5 \% \mathrm{CO}_{2}$ in Dulbecco's modified Eagle's medium plus $10 \%$ fetal calf serum and $100 \mu \mathrm{g}$ of penicillin and streptomycin per $\mathrm{ml}$. The cells were transfected at $50 \%$ confluence.

Transfections. Transfection experiments were performed by the calcium phosphate precipitation technique as described previously $(31,54)$. Briefly, the transfection mix for one 6-cm-diameter plate of HeLa cells included $5 \mu \mathrm{g}$ of CAT reporter construct, $5 \mu \mathrm{g}$ of effector construct, $0.5 \mu \mathrm{g}$ of E1A expression plasmid (pCMV12S.FS or pCMV12S), and $1 \mu \mathrm{g}$ of pON260 with salmon sperm DNA added as the carrier to bring the total to $20 \mu \mathrm{g}$ of DNA. The DNA was applied directly as a calcium phosphate precipitate to the medium of cells that were passaged the previous day. After $16 \mathrm{~h}$, the medium was removed, the cells were washed with phosphate-buffered saline, and fresh medium was applied. In the assay for E1A 243R transactivation, the CAT reporter construct and effector construct, if necessary, were cotransfected into HeLa cells with a plasmid (pCMV12S) that 
A

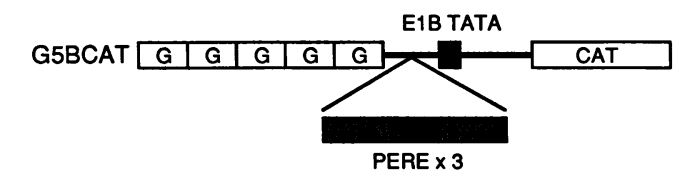

B

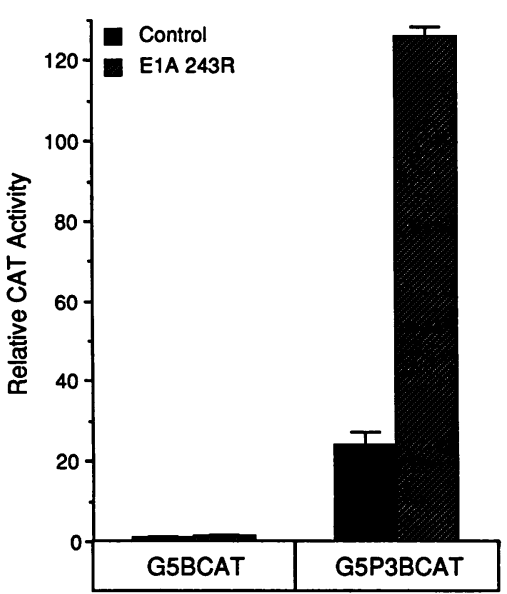

FIG. 1. The PERE is a portable E1A 243R-responsive element. (A) Schematic of G5BCAT and G5P3BCAT. The G5BCAT construct contains the adenovirus E1B TATA motif downstream of five GAL4 sites (44). An oligonucleotide corresponding to three copies of the PERE was inserted into the G5BCAT construct between the GAL4 sites and the TATA motif to create G5P3BCAT. (B) Responses of G5BCAT and G5P3BCAT to E1A 243R. The constructs illustrated in panel A were cotransfected into $\mathrm{HeLa}$ cells with pCMV12S.FS (control) or pCMV12S (E1A 243R). The normalized CAT activity (CAT/B-galactosidase units) obtained with each construct is shown with and without coexpression of E1A 243R. The results represent a single experiment performed in triplicate with the indicated standard deviation. Similar results were obtained in a second transfection performed in triplicate.

expresses E1A 243R and compared with an identical transfection with pCMV12S.FS that expresses only 22 amino acids of E1A 243R sequence.

CAT and $\beta$-galactosidase assays. Cell extracts from one 6-cm-diameter plate were prepared at $48 \mathrm{~h}$ posttransfection by three cycles of freeze-thawing in $100 \mu \mathrm{l}$ of $0.25 \mathrm{M}$ Tris-HCl (pH 8.0). CAT assays (26) were performed in $100 \mu \mathrm{l}$ with variable amounts of extract to obtain results within the linear range (maximum of $50 \mu \mathrm{l}$ extract per assay). Thinlayer chromatograms were quantified with an Ambis Beta Scanner. One unit of CAT activity corresponds to $1 \%$ acetylation of chloramphenicol by $50 \mu \mathrm{l}$ of cell extract in $1 \mathrm{~h}$. In most cases, the CAT results were normalized to the levels of $\beta$-galactosidase. Assays for $\beta$-galactosidase were performed as described previously (30).

RNA analysis. Cytoplasmic RNA isolation and RNase protection assays were performed as described previously (55), with two minor differences. The RNA was isolated at 36 $\mathrm{h}$ posttransfection, and the hybridization volume was $10 \mu \mathrm{l}$. The PCNA-CAT RNA probe was described previously (54). The E1A RNA probe was prepared by SP6 transcription of an XbaI-Bst NI fragment of pCMV12S (nucleotides 1339 to 1464 of the adenovirus genome [24]) inserted into $X b a \mathrm{I}$ HincII-digested pGEM-1. RNA probes were purified by gel electrophoresis.
A.

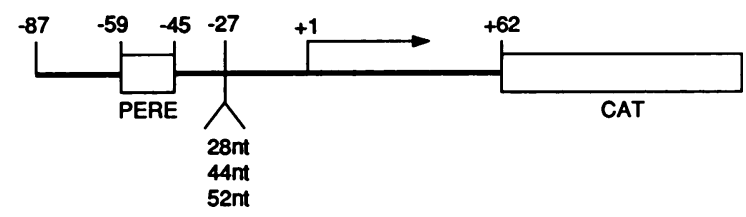

B.

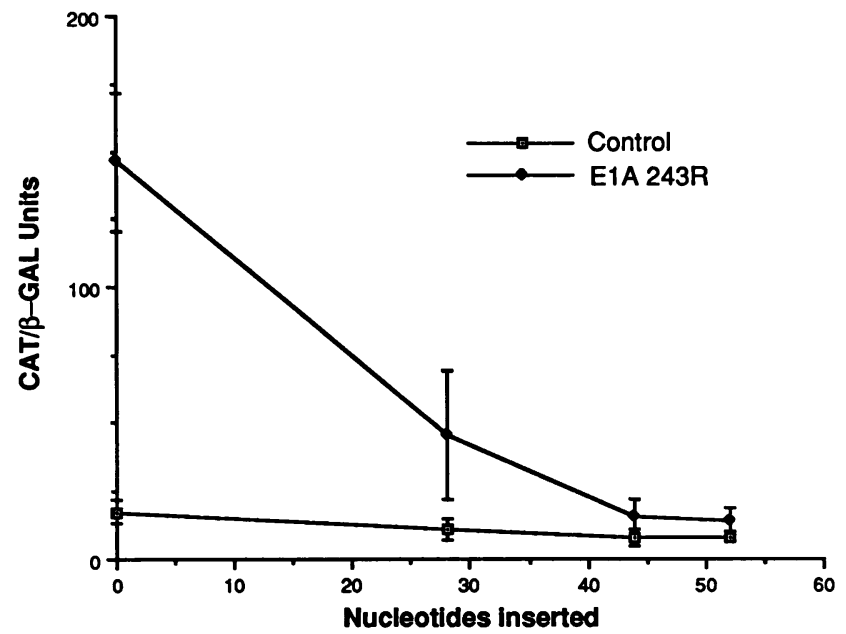

FIG. 2. The insertion of linker DNA between the PERE and the transcriptional initiation site in the PCNA promoter reduces the response to E1A 243R. (A) Schematic of linker insertions in the $-87-+62$ PCNA-CAT construct. Multimerized $\mathrm{XbaI}$ linker DNA was inserted at a site 27 nucleotides upstream $(-27)$ of the transcriptional initiation site (designated +1 ) into a PCNA-CAT reporter construct with 62 nucleotides of transcribed PCNA sequence fused to a CAT reporter gene (boxed) and 87 nucleotides of upstream sequence. The PERE ( -59 to -45 ) is also boxed. (B) Responses of the linker insertion constructs to E1A 243R. The PCNA-CAT constructs shown in panel A were cotransfected into HeLa cells with pCMV12S.FS (control) or pCMV12S (E1A 243R). The normalized CAT activity (CAT/ $\beta$-galactosidase ( $\beta-\mathrm{Gal}$ ) units) obtained for each transfection is shown on the ordinate plotted against the number of nucleotides inserted into the PCNA-CAT construct. The $\mathrm{CAT} / \beta$-galactosidase value represents the average of three different transfections performed in duplicate with a standard deviation indicated by the error bars.

\section{RESULTS}

The PERE is a portable E1A 243R-inducible element. Our previous work showed that mutations within the PERE (nucleotides -59 to -45 upstream of the transcription initiation site) in the human PCNA promoter abrogated transactivation of the promoter by adenovirus E1A 243R and perturbed binding to nuclear proteins (41). We first asked whether the PERE can function autonomously to confer responsivity to E1A $243 R$, or whether cooperation with specific basal promoter elements of the TATA-less PCNA promoter is required. To address this question, the PERE was tested for its ability to confer transactivation by E1A 243R upon a heterologous promoter in a transient expression assay. The G5BCAT construct (44), which contains five GAL4 sites upstream of the adenovirus E1B TATA motif (Fig. 1A), failed to respond to the transactivating effects of E1A 243R (Fig. 1B). Insertion of three tandemly repeated PERE sites immediately upstream of the TATA motif in 
A
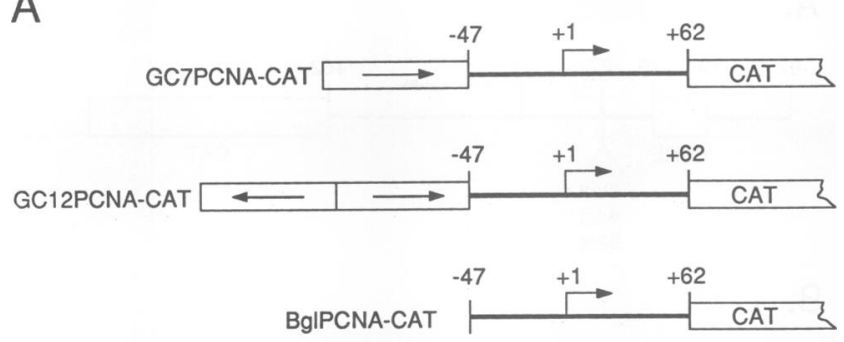

B
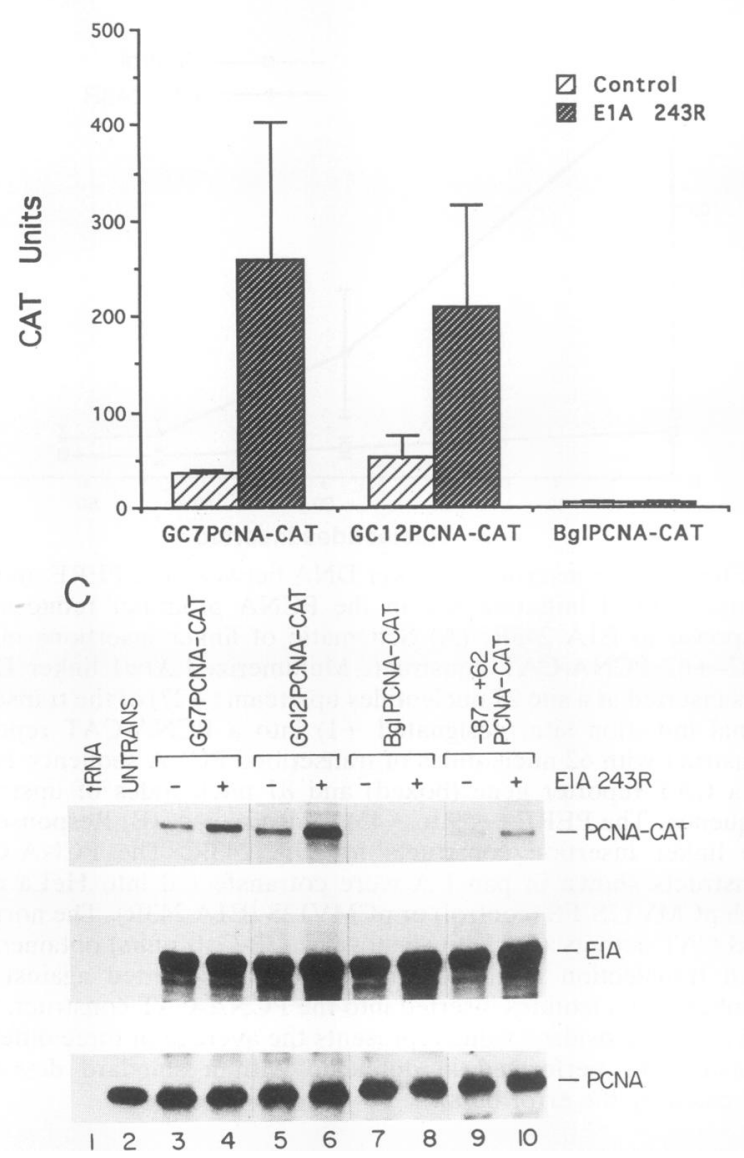

FIG. 3. A fragment of the SV40 enhancer can replace the PERE in the response of the PCNA promoter to E1A. (A) Schematic of PCNA-CAT constructs with SV40 enhancer DNA. An SV40 enhancer fragment with six Sp1 sites was fused upstream of a PCNA-CAT construct containing PCNA sequences from -47 to +62 relative to the site of transcription initiation $(+1)$ to create GC7PCNA-CAT. Sequencing of GC7PCNA-CAT revealed that an additional Sp1 binding site was formed at the end distal to the transcription initiation site upon insertion of a single SV40 enhancer fragment to form GC7PCNA-CAT. The SV40 fragment is indicated by a box, and the arrow indicates that the orientation of the enhancer fragment in GC7PCNA-CAT is identical to its orientation in the SV40 genome relative to the SV40 late promoter. GC12PCNA-CAT contains two copies of the SV40 enhancer fragment upstream of the PCNA-CAT basal promoter in the indicated orientations. The BglPCNA-CAT construct is identical to the other two plasmids except that it lacks SV40 sequences. (B) Responses of GC7PCNA-CAT and GC12PCNA-CAT to E1A 243R. The PCNACAT constructs shown in panel A were cotransfected into HeLa cells with pCMV12S.FS (control) or pCMV12S (E1A 243R). The histograms indicate the average and standard deviation in CAT
G5BCAT (Fig. 1A) produced a marked increase in basal expression (Fig. 1B). Moreover, coexpression of E1A 243R enhanced CAT expression from the G5P3BCAT construct approximately fivefold (Fig. 1B), indicating that the PERE constitutes a portable E1A 243R-inducible element. This response to E1A is not a general phenomenon associated with transcriptional activation of the G5BCAT construct, as other transcriptional activators expressed as GAL4 fusion proteins failed to mediate activation of G5BCAT by E1A 243R (see below). We conclude that the PERE is necessary and sufficient for the response of the PCNA promoter to E1A 243R.

Transactivation of the PCNA promoter through the PERE is position specific. The ability of the PERE to mediate transactivation by E1A 243R was independent of its orientation (not shown), suggesting that it may have enhancer-like properties as suggested previously (58). As such, the action of the PERE should be relatively insensitive to changes in its position within the promoter. To examine the effects of relocating the PERE on its ability to render a response to E1A 243R, we prepared a series of constructs with increasing lengths $(28,44$, and 52 nucleotides) of linker DNA inserted at a position 27 nucleotides upstream of the transcription initiation site (Fig. 2A). The insertions disrupt a region of the promoter that has no qualitative or quantitative effect on expression of PCNA-CAT mRNA and lie immediately upstream of the promoter sequences participating in selection of the transcription initiation site (41). Progressive displacement of the PERE from the transcription initiation site produced slight decreases in the basal level of CAT activity but profoundly reduced the induction of PCNA-CAT by E1A 243R (Fig. 2B). The decline in the E1A 243R response appears to correlate with the separation of the PERE from the transcriptional initiation site rather than with the placement of the PERE on a nonfunctional face of the DNA helix, since the 52-nucleotide insertion is an integral number of turns of the DNA helix (five turns at $10.4 \mathrm{bp}$ per turn). Thus, positioning the PERE near the site of transcriptional initiation potentiates a response to E1A 243R.

The GC-rich sequences of the SV40 enhancer can mediate the E1A 243R response. The preceding results indicate that the PERE functions as an E1A 243R-responsive element in a promoter-proximal location. Transcriptional activators can be classified on the basis of their ability to activate transcription from remote or promoter-proximal positions (69). Since the PERE activates transcription as a promoter-proximal

activity of three transfections performed in duplicate for the indicated reporter constructs. (C) The transcription initiation site in GC7PCNA-CAT and GC12PCNA-CAT corresponds to that of wildtype PCNA-CAT. Total cytoplasmic RNA prepared from HeLa cells transfected with a CAT reporter plasmid and an E1A-expressing plasmid was assayed by RNase protection with probes for PCNA-CAT and E1A mRNA. The lane headings designate the CAT reporter construct used in the transfection. Plasmid -87-+62 PCNA-CAT (lanes 9 and 10) was used for control purposes to demonstrate the transcription initiation site and the response to E1A 243R of the wild-type PCNA-CAT reporter construct. The - and + lane headings indicate whether or not E1A 243R was expressed in the transfected cells. Designations for the RNase protection products from PCNA-CAT, E1A, and the endogenous PCNA mRNAs are shown on the right. The E1A protection product in the - lanes is derived from pCMV12S.FS and does not encode a functional E1A protein. Lanes 1 and 2 display the results of control RNase protection assays for tRNA and RNA from untransfected HeLa cells, respectively. 
element (Fig. 2), perhaps E1A 243R targets this class of transcriptional activators; if so, then other promoter-proximal elements might be able to substitute for PERE function. Sp1 is a ubiquitously expressed transcriptional activator previously shown to activate transcription from TATA-less promoters as well as TATA-containing promoters $(61,78)$. The PCNA promoter possesses a number of sites upstream of nucleotide -100 with homology to the sequence bound by Sp1 (54), but in some instances, Sp1 requires a promoterproximal location to activate transcription $(68,69)$. To determine whether the PERE is obligatorily involved in the E1A response, a 65-nucleotide fragment of the SV40 enhancer containing six copies of the sequence motif recognized by Sp1 (GCGGG) was substituted for the PERE and sequences upstream in the PCNA promoter (GC7PCNACAT; Fig. 3A). The SV40 fragment activated expression of CAT (Fig. 3B) when fused upstream of PCNA promoter sequences ranging from -47 to +62 relative to the transcriptional initiation site (BglPCNA-CAT; Fig. 3A). Two copies of the SV40 enhancer fragment containing 12 copies of the $\mathrm{Sp} 1$ site activated the promoter to a similar extent (GC12PCNA-CAT; Fig. 3). Coexpression of E1A 243R boosted CAT expression in both cases from four- to sevenfold but did not activate CAT expression from BglPCNACAT (Fig. 3B). To ensure that the increase in CAT expression from these artificial promoter constructs correlated with an increase in correctly initiated PCNA-CAT mRNA, RNase protection assays were performed on total cytoplasmic RNA from the transfected cells. As shown in Fig. 3C, the inserted SV40 enhancer did not alter the site of transcription initiation, and coexpression of E1A 243R increased the amount of correctly initiated PCNA-CAT mRNA. Simultaneous control assays for endogenous PCNA mRNA and the coexpressed E1A mRNA indicated that both the amount of RNA assayed and the transfection efficiency were similar in the transfections (Fig. 3C).

Sp1 can mediate the E1A 243R response. Although the SV40 enhancer fragment used in the experiments described above contains several sites corresponding to the Sp1 consensus sequence, there is no assurance that the observations made with GC7PCNA-CAT or GC12PCNA-CAT reflect Sp1 activity rather than the activity of some other HeLa cell protein that binds within the SV40 enhancer fragment. To reduce the complexity of factors that can bind upstream of the PCNA basal promoter $(-47$ to +62$)$ and ensure activation by a specific transcriptional activator, we created G5PCNA-CAT by substituting five copies of the sequence corresponding to the recognition site of the yeast GAL4 protein for the PERE and sequences upstream (Fig. 4). The G5PCNA-CAT construct can bind various effectors expressed as fusions with the DNA binding domain of the yeast GAL4 protein as schematized in Fig. 4A. Through this means, the modular nature of transcription factors (60) permits them to be redirected to a novel site by replacing the natural DNA binding domain of the protein with that of the GALA protein. Thus, specific transcriptional activators (depicted in Fig. 4B) can be assessed for their effects on G5PCNA-CAT in the presence and absence of E1A 243R and also compared with a PCNA basal promoter construct that cannot bind effector, BglPCNA-CAT, and with a heterologous basal promoter that can bind effector, G5BCAT (Fig. 4C).

Confirming the results in Fig. 3, coexpression of a GAL4Sp1 chimera activated expression of both promoter constructs containing upstream GALA sites, G5PCNA-CAT and G5BCAT, but did not activate the construct lacking GAL4 sites, BglPCNA-CAT (not shown). Furthermore, coexpression of GAL4-Sp1 and E1A had no significant effect on CAT expression from BglPCNA-CAT (Fig. 5). Although GAL4Sp1 activated CAT expression from G5BCAT, it did not mediate a response to E1A 243R (Fig. 5). In contrast, coexpression of E1A $243 \mathrm{R}$ produced a five- to sixfold increase in CAT expression from the G5PCNA-CAT construct in the presence of GAL4-Sp1 (Fig. 5). These results also contrast with the results discussed above demonstrating that activation of G5BCAT with the PERE conferred a response to E1A (Fig. 1). The G5PCNA-CAT construct activated by GAL4-Sp1 specified a transcription initiation site for PCNA-CAT mRNA that corresponds to the transcription initiation site specified by the wild-type PCNA promoter $(-1265-+62$ PCNA-CAT), and coexpression of E1A 243R increased the amount of correctly initiated PCNA-CAT mRNA (not shown).

$\mathrm{Sp} 1$ contains a number of functional domains (14). The $\mathbf{N}$ terminus, which includes the DNA binding motif of Sp1, is absent in the GAL4-Sp1 construct, but over 500 amino acids of Sp1, including two transcriptional activation domains, are expressed in the GAL4-Sp1 fusion protein. To relate the region of $\mathrm{Sp} 1$ that confers a response to E1A 243R upon G5PCNA-CAT to its transcription activation function, we coexpressed a construct as a GALA fusion protein that contains amino acids 339 to 500 of Sp1, GAL4-Sp1Q. This fragment of $\mathrm{Sp1}$, which corresponds to the glutamine-rich transcriptional activating region $B$ of the protein (14), also conferred a response to E1A 243R upon G5PCNA-CAT. As shown by the unresponsiveness of BglPCNA-CAT and G5BCAT, the effect of E1A 243R was dependent on the presence of GAL 4 binding sites and promoter specific (Fig. 6). This result suggests that the function of $S p 1$ required for the E1A 243R response of G5PCNA-CAT correlates with transcriptional activation.

Activator-dependent modulation of the PCNA promoter by E1A 243R. Although the data indicate that Sp1 bound upstream of the PCNA basal promoter can substitute for the effect of the PERE in the context of the PCNA promoter, it could not do so in the context of the E1B promoter. To further explore the role of transcriptional activators in the response of G5PCNA-CAT to E1A 243R, a number of GAL4 fusion proteins with acidic activation domains of increasing strength (Fig. 4B) were coexpressed with the three reporter constructs shown in Fig. 4C. As shown in Fig. 7A, none of the acidic effectors had an effect on CAT expression from the PCNA-CAT construct without GAL4 sites (BglPCNACAT). Expression of a truncated GALA protein [GALA(194)] that can bind the GAL4 sites but lacks an activation domain (3) did not activate transcription from any of the three reporter constructs (Fig. 7). The other GALA fusion proteins activated both the G5BCAT (Fig. 7B) and G5PCNA-CAT (Fig. 7C) constructs to an increasing degree, with the order GAL4 REGII > GAL4 REGI > GAL4 AH > GAL4(1-147).

Each reporter construct-activator combination was also assayed in the presence of E1A 243R. As expected, none of the activators elicited a significant E1A effect on promoter activity from BglPCNA-CAT, which lacks GALA binding sites (Fig. 7A). Furthermore, expression of GALA(1-94) did not mediate an E1A effect with the G5BCAT or the G5PCNA-CAT reporter construct (Fig. 7B and C). With each of the GAL4 activators, however, E1A 243R uniformly exerted a repressive effect on the G5BCAT reporter construct (Fig. 7B). In contrast, E1A transactivated G5PCNACAT three- to fivefold in the presence of the relatively weak 


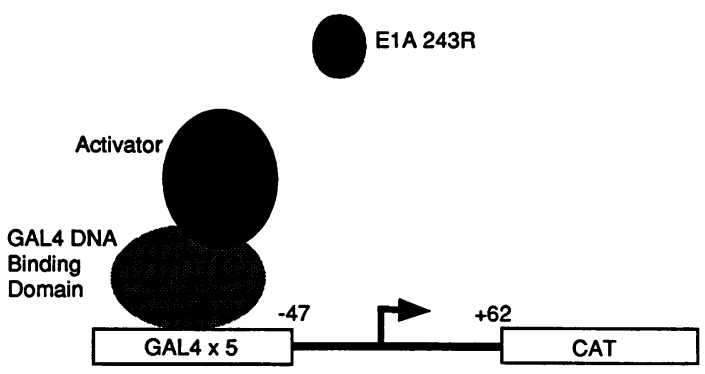

B

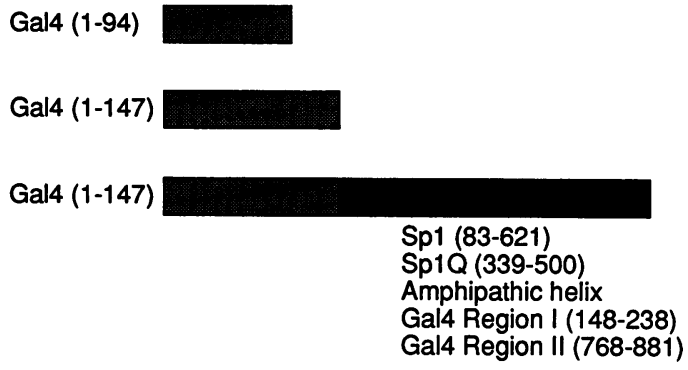

C

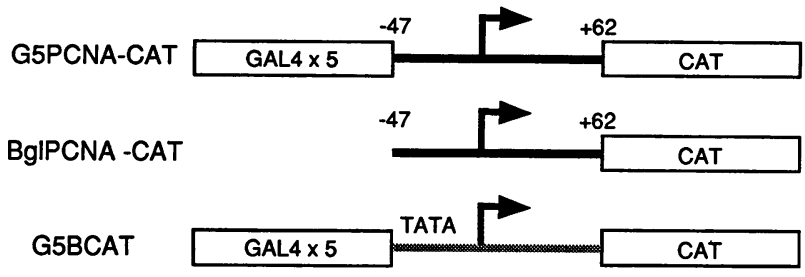

FIG. 4. Experimental design and constructs for testing chimeric activators. (A) Experimental design. Five sites corresponding to the sequence recognition motif for the GAL4 protein were inserted upstream of the PCNA basal promoter $(-47-+62)$ linked to a CAT reporter. Various effectors expressed as fusion proteins with the DNA binding domain of the GAL4 protein (shaded) bind the GALA sites and activate transcription with a heterologous activation domain (black). E1A 243R is coexpressed to determine its effect on activation by the GAL4 fusion protein. The arrow indicates the transcription initiation site. (B) Schematic of effectors. Various fusion proteins with the GAL4 DNA binding domain (shaded) and a heterologous activation domain (black) were cotransfected with one of the three reporter plasmids diagrammed in panel $\mathrm{C}$ in the presence and absence of a plasmid that expresses E1A 243R. GAL4(1-94) binds DNA but does not activate transcription (46a). All other constructs are expressed as derivatives of the GAL4(1147) protein. The numbers in parentheses correspond to the portion of the indicated protein expressed in the fusion protein. The amino-terminal residue of the parent protein would be designated amino acid 1. GAL4(1-147) binds DNA and activates transcription weakly (46a). Sequences of Sp1 that are required for DNA binding (positions 1 to 82) are deleted in GAL4-Sp1 (14). The GAL4-Sp1Q fusion protein possesses the B transcriptional activation domain of Sp1 (14). The amphipathic helix is a construct with an artificial transcriptional activation domain with acidic residues along one face of an $\alpha$ helix (25). GAL4 region I and GAL 4 region II are acidic activation domains of the GAL4 protein (46a). (C) Diagram of reporter plasmids. Three different reporter plasmids were cotransfected with the effectors indicated in panel $B$ in the presence and absence of coexpressed E1A 243R. G5PCNA-CAT contains five sites corresponding to the sequence recognition motif for the GAL4 DNA-binding protein upstream of the PCNA basal promoter ( -47 to transcriptional activators, GAL4(1-147) and GAL4 AH (Fig. 7C). As for the Sp1 transcriptional activation domain, it appears that these weak acidic transcriptional activation domains can substitute for the PERE in the response of G5PCNA-CAT to E1A 243R. By contrast, the strong acidic transcriptional activation domains present in GAL4 REGI and GAL4 REGII did not substitute for PERE function, since E1A 243R reduced the activation properties of these strong activators with G5PCNA-CAT (Fig. 7C). An RNase protection analysis for PCNA-CAT mRNA indicated that the acidic transcriptional activators had no effect on selection of the transcriptional initiation site in G5PCNA-CAT whether or not E1A 243R was coexpressed (Fig. 7D). These data indicate that the response of G5PCNA-CAT to E1A 243R correlates with the strength of transcriptional activation and that weak, but not strong, transcriptional activators of the PCNA-CAT can substitute for the PERE in the response of the PCNA promoter to E1A 243R. Further experiments will be required to show that the activation strength of the effector is indeed the critical determinant for the response to E1A 243R by G5PCNA-CAT. Nevertheless, the PERE is required to confer responsivity to E1A 243R upon G5BCAT, and a variety of GALA fusion proteins cannot replace this function.

\section{DISCUSSION}

In this report, we show that the PERE, previously identified by mutagenesis as an element in the human PCNA promoter that is important for induction by the adenovirus E1A 243R product (41), is necessary and sufficient to confer transactivation by E1A 243R upon a heterologous promoter (E1B). The PERE also serves this function in the natural PCNA promoter, but under special circumstances, it can be functionally replaced by other transcription factor binding sites. In the absence of the PERE, weak transcriptional activation domains of both the glutamine-rich and acidic types permit stimulation of the basal PCNA promoter by E1A 243R, whereas strong acidic transcriptional activators do not. Since the response to E1A 243R varies with effectors that activate transcription to different degrees and is not restricted to a particular class of activator, it appears that E1A 243R modulates transcription on the basis of the strength of activation. This inference must be considered provisional, however, as the activators also differ in other respects. An E1A 243R response is not simply a product of weak transcriptional activation, however, as the weakly activating effectors do not mediate an E1A 243R response with the E1B promoter. These data define two components of the E1A 243R response of the PCNA promoter. One, the PERE, mediates E1A 243R transactivation in the absence of other PCNA promoter elements, and the other, the PCNA basal-promoter, depends on proximal effectors to be transactivated by E1A 243R.

The PERE and transactivation by E1A 243R. The PERE consists of 15 nucleotides. Its downstream portion contains a sequence with near perfect homology (seven of eight nucleotides; TGACGTCG) to the consensus sequence for the binding site of ATF (TGACGTCA). The ATF site

+62) fused to a CAT reporter gene. BglPCNA-CAT is an identical construct that lacks the GAL4 sites. G5BCAT contains five GAL4 sites upstream of the adenovirus E1B TATA sequence linked to CAT reporter sequences (44). 


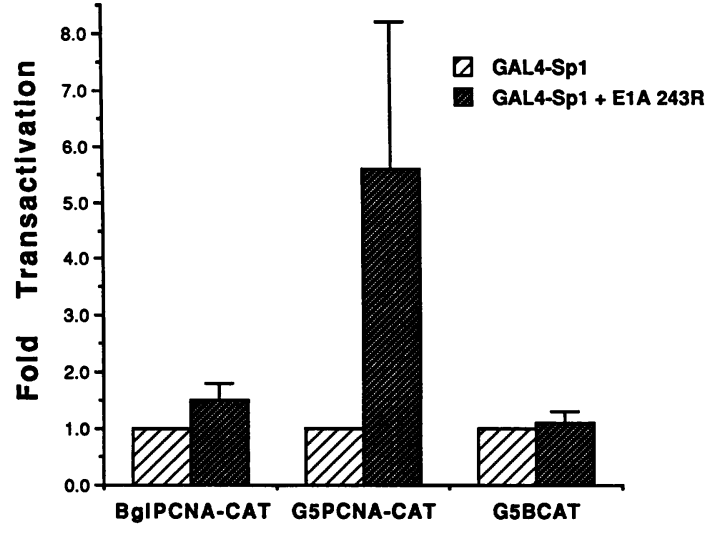

FIG. 5. Activation of G5PCNA-CAT by GAL4-Sp1 confers a response to E1A 243R. Responses of three reporter plasmids to E1A 243R with GAL4-Sp1 are shown. Each of the three reporter constructs diagrammed in Fig. $4 \mathrm{C}$ was cotransfected into HeLa cells with a construct that expressed the GAL4-Spl fusion protein (Fig. 4B) and pCMV12S.FS (control) or pCMV12S (E1A 243R). The CAT activity for each assay was corrected for transfection efficiency with the $\beta$-galactosidase activity expressed from a fourth plasmid, pON260, included in the transfection mix. The result obtained in the absence of E1A 243R with GAL4-Sp1 for each reporter was arbitrarily assigned the value of 1 (broad stripes). In four transfections, the average CAT/ $\beta$-galactosidase units for basal transcription (in the presence of GAL4-Sp1 and pCMV12S.FS) with the BglPCNA-CAT, G5PCNA-CAT, and G5BCAT reporters were 2.4, 10.5, and 22.6, respectively. The graph shows the change (fold transactivation with the indicated standard deviation) induced by coexpression of E1A 243R (narrow stripes) for each of the indicated reporter constructs. The results are averages of four different transfections performed in duplicate.

appears to contribute to PERE function, since a fournucleotide change at the core of the ATF palindrome prevents transactivation of the PCNA promoter and disrupts binding of nuclear proteins to the PERE (41, 55). An oligonucleotide corresponding to the PERE forms multiple complexes with nuclear extracts from human cell lines in gel mobility shift assays (40a). The complicated gel shift pattern possibly relates, at least in part, to the ATF site, which could presumably bind members of the ATF family (28), including immunologically related AP-1 and CREB (27), as specific homo- and heterodimers, as well as the CCAAT/enhancerbinding protein $(5,29,85)$. However, it is presently unclear which members of the ATF family, if any, bind the PERE and mediate transactivation by E1A 243R. The PERE also displays some sequence homology (a five-of-eight match) to an E1A 243R-responsive site in the c-jun promoter, the jun2TRE (TTACCTCA), which binds a heterodimer of c-Jun and ATF-2 in vitro (86). Like the PERE, the jun2TRE can also mediate transactivation of a heterologous promoter by E1A 243R (86). Although the homology between the PERE and the jun2TRE is limited, the E1A 243R-responsive c-Jun/ ATF-2 heterodimer can also bind an ATF palindrome (TGACGTCA) (5), which more closely resembles the downstream part of the PERE sequence (a seven-of-eight match).

The presence of an ATF site alone is not sufficient to mediate a stimulatory response to E1A 243R. Four of the five adenovirus early genes possess sites with homology to the ATF motif (38), but they are repressed by coexpression of E1A 243R in HeLa cells (15). If ATF family members bind the PERE, two of its features might distinguish it from other ATF sites and endow it with the capacity to mediate trans-

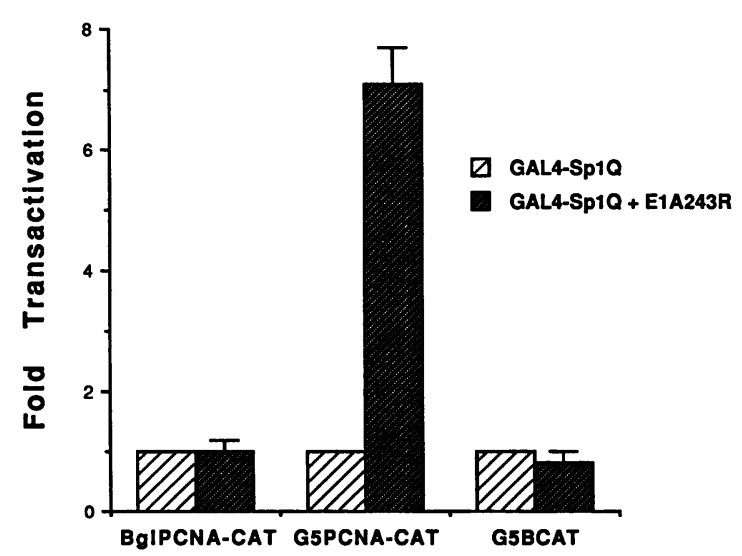

FIG. 6. The activation domain of $\mathrm{Sp} 1$ promotes transactivation by E1A 243R. Details are as for Fig. 5 except that the GAL4-Sp1Q fusion protein (Fig. 4B) instead of GAL4-Sp1 was expressed in the transfected cells. The results shown are the averages of three different transfections performed in duplicate. In three transfections, the average CAT/ $\beta$-galactosidase units for basal transcription (in the presence of GAL4-Sp1Q and pCMV12S.FS) for the BglPCNA-CAT, G5PCNA-CAT, and G5BCAT reporters were 6.2, 24.5 , and 104.2 , respectively.

activation by E1A 243R: the upstream portion of the PERE (41), and its promoter-proximal positioning (Fig. 2). The sequence upstream of the ATF homology in the PERE could specify the binding of a particular ATF dimer (16). Alternatively, these sequences could serve as the binding site for a different protein that binds cooperatively with proteins bound at the ATF site. The Ets proteins $(8,49)$ and the herpesvirus transactivator protein, VP16 (81), are examples of DNA-binding proteins that employ such a strategy. The importance of the second distinctive property of the PERE, its promoter-proximal position, is illustrated by the diminished response to E1A 243R of constructs with linker sequences inserted between the PERE and the transcriptional initiation site (Fig. 2). Although the PERE may have enhancer-like properties $(58)$, the ability to mediate a response to E1A 243R is sensitive to location. The conservation of the location of the PERE in the PCNA promoters from rat, mouse, and human genes (73) also suggests that a promoterproximal location is critical to its function.

The PERE is among a limited number of DNA elements known to confer an E1A 243R response upon an unresponsive promoter. Nevertheless, a number of weakly activating GALA fusion proteins can mediate E1A 243R transactivation of the PCNA basal promoter. A simple interpretation of this apparent inconsistency would be that there is an additional E1A 243R-responsive element in the PCNA basal promoter fragment $(-47$ to +62$)$. In this regard, homologies to binding sites for YY1, a known E1A 243R-responsive transcription factor, reside in the -47 to +62 region $(41,54)$. With the caveat that cryptic E1A 243R-responsive sites might have been created by the mutations, mutagenesis of these sites and more extensive linker-scanning mutagenesis throughout the -47 to +62 region did not reveal an additional E1A 243R-responsive element. Other reported activities of E1A that might account for transactivation of G5PCNA-CAT, such as dissociation of TBP from Dr1 (34) or a previously proposed general transcription activation function (83), seem too general to account for the specificity of transactivation for the PCNA promoter. 


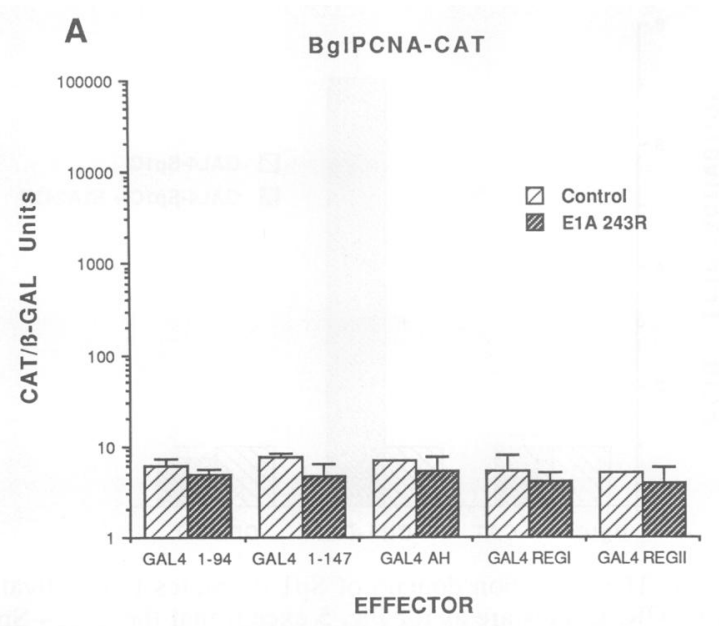

C

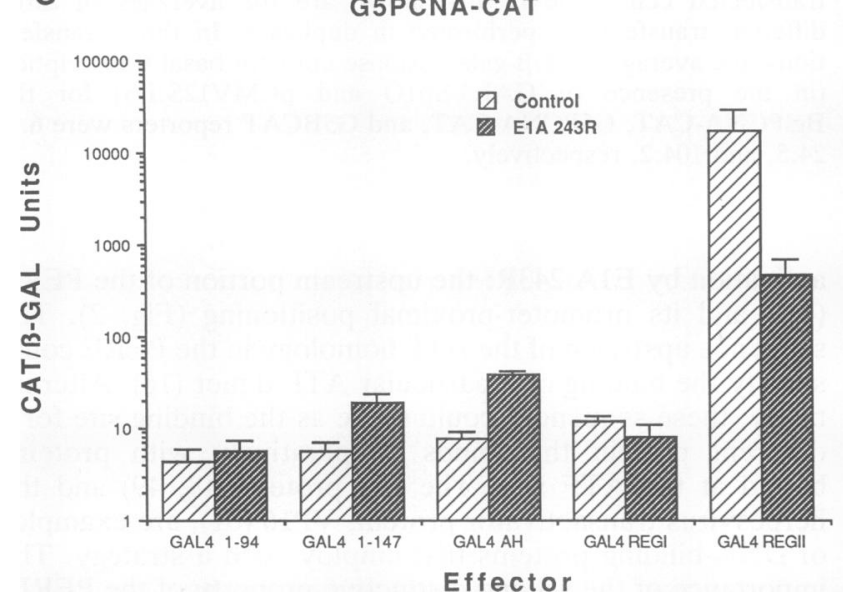

B

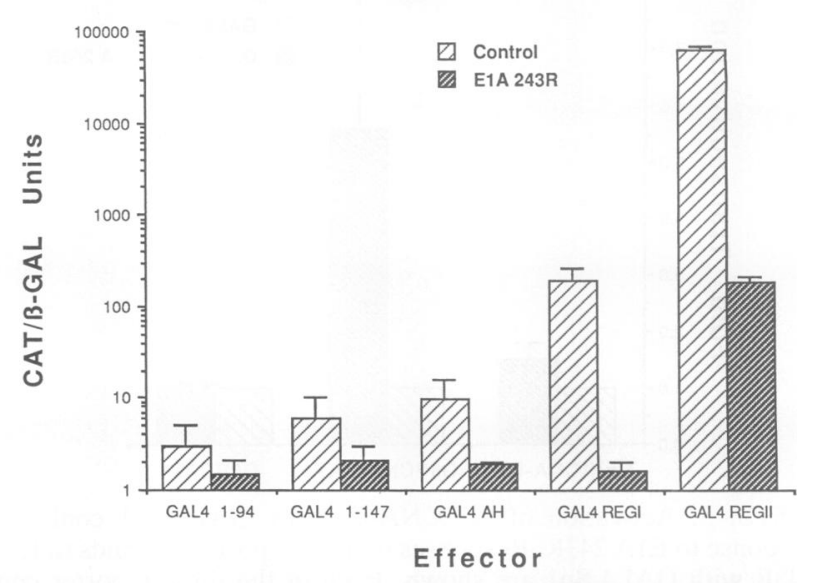

D
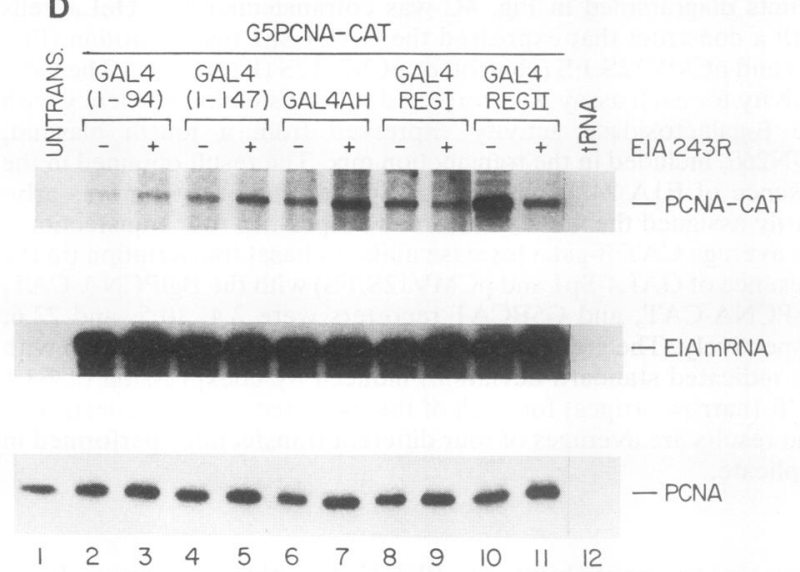

FIG. 7. The E1A 243R oncoprotein can modulate activation of the PCNA basal promoter by acidic effectors. The three reporters shown in Fig. 4C were assayed as in Fig. 5 with the indicated effector (diagrammed in Fig. 4C) in the presence (E1A 243R) and absence of E1A 243R expression (control). The CAT/ $\beta$-galactosidase ( $\beta$-GAL) values (shown on a log scale) are plotted directly as the average of two transfections performed in duplicate. (A) Acidic effectors with the BgIPCNA-CAT reporter; (B) acidic effectors with the G5BCAT reporter; (C) acidic effectors with the G5PCNA-CAT reporter; (D) RNase protection assays of RNA from cells transfected with the G5PCNA-CAT reporter and the acidic effectors. Total cytoplasmic RNA was prepared at $36 \mathrm{~h}$ posttransfection from HeLa cells cotransfected with G5PCNA-CAT, an E1A expression plasmid (pCMV12S.FS or pCMV12S), and the indicated effector. The RNA recovered from one 6-cm-diameter plate was assayed by RNase protection with probes for PCNA-CAT and E1A mRNAs. The lane headings with brackets indicate the effector expressed in the transfection assay. The - lane headings (even-numbered lanes excluding lane 12) indicate the samples from cells transfected with pCMV12S.FS (no E1a 243R), and the + lane headings (odd-numbered lanes excluding lane 1) indicate the samples from cells transfected with pCMV12S (E1A 243R). The RNase protection products corresponding to PCNA-CAT, E1A, and the endogenous PCNA mRNAs are shown and identified on the right. The protection products of control assays with RNA from untransfected HeLa cells (lane 1) and tRNA (lane 12) are also shown.

Features of the PCNA basal promoter that permit transactivation by E1A 243R. The basal promoter of the E1A 243R-responsive G5PCNA-CAT construct differs from the basal promoter of the E1A 243R-unresponsive G5BCAT in that the PCNA promoter lacks a clearly defined TATA motif. Like TATA-containing promoters, TATA-less promoters also require TFIID to initiate transcription $(10,62$, 78), and there is evidence that bacterially expressed TBP binds TATA-less promoter sequences about 30 nucleotides upstream from the transcription initiation site in vitro (92). The sixfold reduction in affinity of TBP for TATA-less promoters (92) suggests a model in which transactivation by E1A 243R stems from an ability to augment the interaction of the weak effectors with TBP and thereby increase the efficiency of binding of TBP to the template. In this model, promoters containing a TATA box would be less susceptible to this mode of E1A 243R activation because TBP can associate stably with the template by direct sequence recognition. This model could also explain our inability to define specific sequences in the PCNA basal promoter that mediate E1A transactivation. In general, the nature of the basal promoter can modify the response to transcriptional activators $(47,88)$, and transactivation by E1A $243 \mathrm{R}$, in particular, can be disrupted by changes in the basal promoter (75). By analogy, the E1A 243R response of G5PCNA-CAT with weak effectors may depend on a feature of the PCNA basal promoter, namely, the absence of a TATA motif.

Like the PCNA promoter, many of the cellular promoters for housekeeping genes are TATA-less (17). The proposed model for activation of TATA-less promoters by E1A 243R 
would provide a means for adenovirus to induce the expression of the housekeeping genes to a level that can support viral growth. In the absence of a productive viral infection, a consequence of chronic induction of these cellular genes would be continued cell growth.

The effector dependence of E1A 243R transactivation. Our data suggest that different effectors can promote the assembly of initiation complexes on the PCNA basal promoter that vary in their response to E1A 243R. This effector dependence can be explained by supposing that E1A 243R (or a factor influenced by it) complements the weak effectors by contacting an additional site in the initiation complex, thereby stabilizing the complex and activating transcription synergistically. Repression of transcription activation by the strong effectors would occur if strong effectors make an equivalent contact in the absence of E1A 243R, and E1A $243 R$ competes for binding to this additional site. In terms of the kinetics of complex formation, synergistic transcriptional activation by E1A 243 R and the weak effectors would occur if the two activators increase the rate of separate rate-limiting steps in the same transcription initiation pathway (32). Strong transcriptional activators might promote the use of an alternate, more efficient transcription initiation pathway (e.g., the use of a different TFIID complex). In this event, the same activity of E1A 243R that complements the weak effectors would interfere with the function of the strong effectors and cause repression by promoting the use of a less efficient transcription initiation pathway.

In support of these models, distinct TFIID complexes that vary in their responses to effectors have been identified (84), and alternate pathways of transcription initiation in a TATAless promoter have been described (20). The proposal that divergent transcriptional initiation pathways are established by effectors of different strengths would provide an explanation for two frequently observed transcriptional effects of E1A 243R. On the one hand, E1A 243R transactivates minimal promoter constructs $(75,76,93$; this report), but it also represses enhancer activity (63). Although we do not know whether E1A 243R acts directly or through other factors, if repression and transactivation are related functions of the protein, the two properties should map to the same domains of E1A 243R. Our current experiments are exploring this possibility.

\section{ACKNOWLEDGMENTS}

We thank Ronnie Packer for excellent technical assistance and Grace Gill and Kathy Martin for GAL4 fusion protein constructs. This work was supported by NCI grant CA13106.

\section{REFERENCES}

1. Almendral, J. M., D. Huebsch, P. A. Blundell, H. MacdonaldBravo, and R. Bravo. 1987. Cloning and sequence of the human nuclear protein cyclin: homology with DNA-binding proteins. Proc. Natl. Acad. Sci. USA 84:1575-1579.

2. Bagchi, S., P. Raychaudhuri, and J. R. Nevins. 1990. Adenovirus E1A proteins can dissociate heteromeric complexes involving the E2F transcription factor: a novel mechanism for E1A trans-activation. Cell 62:659-669.

3. Baleja, J. D., R. Marmorstein, S. C. Harrison, and G. Wagner. 1992. Solution structure of the DNA-binding domain of $C d 2$ GAL4 from S. cerevisiae. Nature (London) 356:450-453.

4. Bandara, L. R., and N. B. La Thangue. 1991. Adenovirus E1A prevents the retinoblastoma gene product from complexing with a cellular transcription factor. Nature (London) 351:494 497.

5. Benbrook, D. M., and N. C. Jones. 1990 . Heterodimer formation between CREB and JUN proteins. Oncogene 5:295-302.
6. Berk, A. J. 1986. Functions of adenovirus E1A. Annu. Rev. Genet. 20:45-79.

7. Bravo, R., R. Frank, P. A. Blundell, and H. Macdonald-Bravo. 1987. Cyclin/PCNA is the auxiliary protein of DNA polymerase- $\delta$. Nature (London) 326:515-517.

8. Brown, T. A., and S. L. McKnight. 1992. Specificities of protein-protein and protein-DNA interaction of GABP $\alpha$ and two newly defined ets-related proteins. Genes Dev. 6:2502-2512.

9. Buratowski, S., S. Hahn, L. Guarente, and P. A. Sharp. 1989. Five intermediate complexes in transcription initiation by RNA polymerase II. Cell 56:549-561.

10. Carcamo, J., L. Buckbinder, and D. Reinberg. 1991. The initiator directs the assembly of a transcription factor IID-dependent complex. Proc. Natl. Acad. Sci. USA 88:8052-8056.

11. Carey, M. 1991. Mechanistic advances in eukaryotic gene activation. Curr. Opin. Cell Biol. 3:452-460.

12. Chang, C.-D., L. Ottavio, S. Travali, K. E. Lipson, and R. Baserga. 1990. Transcriptional and post-transcriptional regulation of the proliferating cell nuclear antigen gene. Mol. Cell. Biol. 10:3289-3296.

13. Conaway, J. W., and R. C. Conaway. 1991. Initiation of eukaryotic messenger RNA synthesis. J. Biol. Chem. 266:17721-17724.

14. Courey, A. J., and R. Tjian. 1988. Analysis of Sp1 in vivo reveals multiple transcriptional domains, including a novel glutamine-rich activation motif. Cell 55:887-898.

15. Déry, C. V., C. H. Herrmann, and M. B. Mathews. 1987. Response of individual adenovirus promoters to the products of the E1A gene. Oncogene 2:15-23.

16. Deutsch, P. J., J. P. Hoeffler, J. L. Jameson, J. C. Lin, and J. F. Habener. 1988. Structural determinants for transcriptional activation by cAMP-responsive DNA elements. J. Biol. Chem. 263:18466-18472.

17. Dynan, W. S. 1986. Promoters for housekeeping genes. Trends Genet. 2:196-197.

18. Dynan, W. S. 1989. Modularity in promoters and enhancers. Cell 58:1-4.

19. Ellis, L., E. Clauser, D. O. Morgan, M. Edery, R. A. Roth, and W. J. Rutter. 1986. Replacement of insulin receptor tyrosine residues 1162 and 1163 compromises insulin-stimulated kinase activity and uptake of 2-deoxyglucose. Cell 45:721-732.

20. Faber, P. W., H. C. J. van Rooij, H. J. Schippert, A. O. Brinkmann, and J. Trapman. 1993. Two different, overlapping pathways of transcription initiation are active on the TATA-less human androgen receptor promoter. J. Biol. Chem. 269:92969301.

21. Ferguson, B., B. Krippl, O. Andrisani, N. Jones, H. Westphal, and M. Rosenberg. 1985. E1A $13 \mathrm{~S}$ and $12 \mathrm{~S}$ mRNA products made in Escherichia coli both function as nucleus-localized transcription activators but do not directly bind DNA. Mol. Cell. Biol. 5:2653-2661.

22. Flint, J., and T. Shenk. 1989. Adenovirus E1A protein paradigm viral transactivator. Annu. Rev. Genet. 23:141-161.

23. Gill, G., I. Sadowski, and M. Ptashne. 1990. Mutations that increase the activity of a transcriptional activator in yeast and mammalian cells. Proc. Natl. Acad. Sci. USA 87:2127-2131.

24. Gingeras, T. R., D. Sciaky, R. E. Gelinas, J. Bing-Dong, C. E. Yen, M. M. Kelly, P. A. Bullock, B. L. Parsons, K. E. O'Neill, and R. J. Roberts. 1982. Nucleotide sequences from the adenovirus-2 genome. J. Biol. Chem. 257:13475-13491.

25. Giniger, E., and M. Ptashne. 1987. Transcription in yeast activated by a putative amphipathic $\alpha$ helix linked to a DNA binding unit. Nature (London) 330:670-672.

26. Gorman, C. M., L. F. Moffat, and B. H. Howard. 1982 Recombinant genomes which express chloramphenicol acetyltransferase in mammalian cells. Mol. Cell. Biol. 2:1044-1051.

27. Hai, T., F. Liu, E. A. Allegretto, M. Karin, and M. R. Green. 1988. A family of immunologically related transcription factors that includes multiple forms of ATF and AP-1. Genes Dev. 2:1216-1226.

28. Hai, T., F. Liu, W. J. Coukos, and M. R. Green. 1989. Transcription factor ATF cDNA clones: an extensive family of leucine zipper proteins able to selectively form DNA-binding heterodimers. Genes Dev. 3:2083-2090. 
29. Hai, T., and T. Curran. 1991. Cross-family dimerization of transcription factors Fos/Jun and ATF/CREB alters DNA binding specificity. Proc. Natl. Acad. Sci. USA 88:3720-3724.

30. Herbomel, P., B. Bourachot, and M. Yaniv. 1984. Two distinct enhancers with different cell specificities coexist in the regulatory region of polyoma. Cell 39:653-662.

31. Herrmann, C. H., and M. B. Mathews. 1989. The adenovirus E1B 19-kilodalton protein stimulates gene expression by increasing DNA levels. Mol. Cell. Biol. 9:5412-5423.

32. Herschlag, D., and F. B. Johnson. 1993. Synergism in transcriptional activation: a kinetic view. Genes Dev. 7:173-179.

33. Horikoshi, M., K. Maguire, A. Kralli, E. Maldonado, D. Reinberg, and R. Weinmann. 1991. Direct interaction between adenovirus E1A protein and the TATA box binding transcription factor IID. Proc. Natl. Acad. Sci. USA 88:5124-5128.

34. Inostroza, J. A., F. H. Mermelstein, I. Ha, W. S. Lane, and D. Reinberg. 1992. Dr1, a TATA-binding protein-associated phosphoprotein and inhibitor of class II gene transcription. Cell 70:477-489.

35. Jaskulski, D., C. Gatti, S. Travali, B. Calabretta, and R. Baserga. 1988. Regulation of the proliferating cell nuclear antigen (cyclin) and thymidine kinase mRNA levels by growth factors. J. Biol. Chem. 263:10175-10179.

36. Jelsma, T. N., J. A. Howe, J. S. Mymryk, C. M. Evelegh, N. F. A. Cunniff, and S. T. Bayley. 1989. Sequences in E1A proteins of human adenovirus 5 required for cell transformation, repression of a transcriptional enhancer, and induction of proliferating cell nuclear antigen. Virology 170:120-130.

37. Johnson, P. F., and S. L. McKnight. 1989. Eukaryotic transcriptional regulatory proteins. Annu. Rev. Biochem. 58:799-839.

38. Jones, N. C., P. W. J. Rigby, and E. B. Ziff. 1988. Trans-acting protein factors and the regulation of eukaryotic transcription: lessons from studies on DNLA tumor viruses. Genes Dev. 2:267-281.

39. Kannabiran, C., G. F. Morris, C. Labrie, and M. B. Mathews. 1993. The adenovirus E1A $12 \mathrm{~S}$ product displays functional redundancy in activating the human proliferating cell nuclear antigen promoter. J. Virol. 67:507-515.

40. Keegan, L., G. Gill, and M. Ptashne. 1986. Separation of DNA binding from transcription-activating function of a eukaryotic regulatory protein. Science 231:699-704.

40a.Labrie, C. Unpublished data.

41. Labrie, C., G. F. Morris, and M. B. Mathews. 1993. A complex promoter element mediates transactivation of the human proliferating cell nuclear antigen promoter by the 243-residue adenovirus E1A oncoprotein. Mol. Cell. Biol. 13:1697-1707.

42. Lee, W. S., C. C. Kao, G. O. Bryant, X. Liu, and A. J. Berk. 1991. Adenovirus E1A activation domain binds the basic repeat in the TATA box transcription factor. Cell 67:365-376.

43. Leff, T., R. Elkaim, C. R. Goding, P. Jalinot, P. Sassone-Corsi, M. Perricaudet, C. Kédinger, and P. Chambon. 1984. Individual products of the adenovirus $12 \mathrm{~S}$ and 13S E1A mRNAs stimulate viral E2A and E3 expression at the transcriptional level. Proc. Natl. Acad. Sci. USA 81:4381-4385.

44. Lillie, J. W., and M. R. Green. 1989. Transcription activation by the adenovirus E1A protein. Nature (London) 338:39-44.

45. Liu, F., and M. R. Green. 1990. A specific member of the ATF transcription factor family can mediate transcription activation by the adenovirus E1A protein. Cell 61:1217-1224.

46. Lum, L. S., S. Hsu, M. Vaewhongs, and B. Wu. 1992. The hsp70 gene CCAAT-binding factor mediates transcriptional activation by the adenovirus E1A protein. Mol. Cell. Biol. 12:2599-2605.

46a.Ma, J., and M. Ptashne. 1987. Deletion analysis of GALA defines two transcriptional activating segments. Cell 48:847853.

47. Mack, D. H., J. Vartikar, J. M. Pipas, and L. A. Laimins. 1993. Specific repression of TATA-mediated but not initiator-mediated transcription by wild-type p53. Nature (London) 363:281283.

48. Maekawa, T., S. Matsuda, J.-I. Fujisawa, M. Yoshida, and S. Ishii. 1991. Cyclic AMP response element-binding protein, CRE-BP1, mediates the E1A-induced but not the Tax-induced trans-activation. Oncogene 6:627-632.
49. Marais, R., J. Wynne, and R. Treisman. 1993. The SRF accessory protein Elk-1 contains a growth factor-regulated transcriptional activation domain. Cell 73:381-393.

50. Martif, K. J., J. W. Lillie, and M. R. Green. 1990. Evidence for interaction of different eukaryotic transcriptional activators with distinct cellular targets. Nature (London) 346:147-152.

51. Matsumoto, K., T. Moriuchi, T. Koji, and P. Nakane. 1987. Molecular cloning of cDNA coding for rat proliferating cell nuclear antigen (PCNA)/cyclin. EMBO J. 6:637-642.

52. Mitchell, P. J., and R. Tjian. 1989. Transcriptional regulation in mammalian cells by sequence-specific DNA binding proteins. Science 245:371-378.

53. Moran, E., and M. B. Mathews. 1987. Multiple functional domains of the adenovirus E1A gene. Cell 48:177-178.

54. Morris, G. F., and M. B. Mathews. 1990. Analysis of the proliferating cell nuclear antigen promoter and its response to adenovirus early region 1 . J. Biol. Chem. 265:16116-16125.

55. Morris, G. F., and M. B. Mathews. 1991. The adenovirus E1A transforming protein activates the proliferating cell nuclear antigen promoter via an activating transcription factor site. $J$. Virol. 65:6397-6406.

56. Mudryj, M., S. W. Hiebert, and J. R. Nevins. 1990. A role for the adenovirus inducible E2F transcription factor in a proliferation-dependent signal transduction pathway. EMBO J. 7:2179_ 2184.

57. Nevins, J. R. 1989. Mechanisms of viral-mediated trans-activation of transcription. Adv. Virus Res. 37:35-83.

58. Pietrzkowski, Z., H. Alder, C.-D. Chang, D. H. Ku, and R. Baserga. 1991. Characterization of an enhancer-like structure in the promoter region of the proliferating cell nuclear antigen (PCNA) gene. Exp. Cell Res. 193:283-290.

59. Prelich, G., M. Kostura, D. R. Marshak, M. B. Mathews, and B. Stillman. 1987. The cell-cycle regulated proliferating cell nuclear antigen is required for SV40 DNA replication in vitro. Nature (London) 326:471-475.

60. Ptashne, M. 1988. How eukaryotic transcriptional activators work. Nature (London) 335:683-689.

61. Pugh, B. F., and R. Tjian. 1990. Mechanism of transcriptional activation by Sp1: evidence for co-activators. Cell 61:11871197.

62. Pugh, B. F., and R. Tjian. 1991. Transcription from a TATAless promoter requires a multisubunit TFIID complex. Genes Dev. 5:1935-1945.

63. Rochette-Egly, L., C. Fromental, and P. Chambon. 1990. General repression of enhanson activity by the adenovirus-2 E1A proteins. Genes Dev. 4:137-150.

64. Roy, A. L., M. Meisterernst, P. Pognonec, and R. G. Roeder. 1991. Cooperative interaction of an initiator-binding transcription initiation factor and the helix-loop-helix activator USF. Nature (London) 354:245-248.

65. Ruley, E. 1990. Transforming collaborations between ras and nuclear oncogenes. Cancer Cells 2:258-268.

66. Sadowski, I., J. Ma, S. Triezenberg, and M. Ptashne. 1988. GAL4-VP16 is an unusually potent transcriptional activator. Nature (London) 335:563-564.

67. Sambrook, J., B. Sugden, W. Keller, and P. A. Sharp. 1973. Transcription of simian virus 40 . III. Mapping of "early" and "late" species of RNA. Proc. Natl. Acad. Sci. USA 70:37113715.

68. Segal, R., and A. J. Berk. 1991. Promoter activity and distance constraints of one versus two Sp1 binding sites. J. Biol. Chem. 266:20406-20411.

69. Seipel, K., O. Georgiev, and W. Schaffiner. 1992. Different activation domains stimulate transcription from remote ('enhancer') and proximal ('promoter') positions. EMBO J. 11: 4961-4968.

70. Seto, E., Y. Shi, and T. Shenk. 1991. YY1 is an initiator sequence-binding protein that directs and activates transcription in vitro. Nature (London) 354:241-245.

71. Shenk, T. 1989. Oncogenesis by DNA viruses: adenoviruses, $p$. 239-257. In R. A. Weinberg (ed.), Oncogenes and the molecular origins of cancer. Cold Spring Harbor Laboratory Press, Cold Spring Harbor, N.Y. 
72. Shi, Y., E. Seto, L.-S. Chang, and T. Shenk. 1991. Transcriptional repression by YY1, a human GLI-Krüppel-related protein, and relief of repression by adenovirus E1A protein. Cell 67:377-388.

73. Shipman-Appasamy, P., K. S. Cohen, and M. B. Prystowsky. 1991. Nucleotide sequence of murine PCNA: interspecies comparison of the cDNA and the $5^{\prime}$ flanking region of the gene. DNA Seq. 2:181-191.

74. Shivji, M. K. K., M. K. Kenny, and R. D. Wood. 1992. Proliferating cell nuclear antigen is required for DNA excision repair. Cell 69:367-374.

75. Simon, M. C., T. M. Fisch, B. J. Benecke, J. R. Nevins, and N. Heintz. 1988. Definition of multiple, functionally distinct TATA elements, one of which is a target in the hsp 70 promoter for E1A regulation. Cell 52:723-729.

76. Simon, M. C., R. J. Rooney, T. M. Fisch, N. Heintz, and J. R. Nevins. 1990. E1A-dependent trans-activation of the c-fos promoter requires the TATAA sequence. Proc. Natl. Acad. Sci. USA 87:513-517.

77. Smale, S. T., and D. Baltimore. 1989. The "initiator" as a transcription control element. Cell 57:103-113.

78. Smale, S. T., M. C. Schmidt, A. J. Berk, and D. Baltimore. 1990. Transcriptional activation by $\mathrm{Spl}$ as directed through TATA or initiator: specific requirement for mammalian transcription factor IID. Proc. Natl. Acad. Sci. USA 87:4509-4513.

79. Spaete, R. R., and E. S. Mocarski. 1985. Regulation of cytomegalovirus gene expression: $\alpha$ and $\beta$ promoters are trans activated by viral functions in permissive human fibroblasts. J. Virol. 56:135-143.

80. Stein, R. W., M. Corrigan, P. Yaciuk, J. Whelan, and E. Moran. 1990. Analysis of E1A-mediated growth regulation functions: binding of the 300 -kilodalton cellular product correlates with E1A enhancer repression function and DNA synthesis-inducing activity. J. Virol. 64:4421-4427.

81. Stern, S., M. Tanaka, and W. Herr. 1989. The oct-1 homoeo domain directs formation of a multiprotein-DNA complex with the HSV transactivator VP16. Nature (London) 341:624-630.

82. Su, W., S. Jackson, R. Tjian, and H. Echols. 1991. DNA looping between sites for transcriptional activation: self-association of DNA-bound Sp1. Genes Dev. 5:820-826.

83. Taylor, I. C. A., and R. E. Kingston. 1990. E1A transactivation of the human hsp70 gene promoter substitution mutants is independent of the composition of upstream and TATA elements. Mol. Cell. Biol. 10:176-183.

84. Timmers, H. T. M., and P. A. Sharp. 1991. The mammalian TFIID protein is present in two functionally distinct complexes. Genes Dev. 5:1946-1956.
85. Vallejo, M., D. Ron, C. P. Miller, and J. F. Habener. 1993. C/ATF, a member of the activating transcription factor family of DNA-binding proteins, dimerizes with CAAT/enhancer-binding proteins and directs their binding to cAMP response elements. Proc. Natl. Acad. Sci. USA 90:4679-4683.

86. van Dam, H., M. Duyndam, R. Rottier, A. Bosch, L. de Vries-Smits, P. Herrlich, A. Zantema, P. Angel, and A. J. van der Eb. 1993. Heterodimer formation of cJun and ATF-2 is responsible for induction of $c$-jun by the 243 amino acid adenovirus E1A protein. EMBO J. 12:479-487.

87. Webster, L. C., and R. P. Ricciardi. 1991. trans-dominant mutant of E1A provide genetic evidence that the zinc finger of the trans-acting domain binds a transcription factor. Mol. Cell. Biol. 11:4287-4296.

88. Wefald, F. C., B. H. Devlin, and R. S. Williams. 1990. Functional heterogeneity of mammalian TATA-box sequences revealed by interaction with a cell-specific enhancer. Nature (London) 344:260-262.

89. Weinmann, R. 1992. The basic RNA polymerase II transcriptional machinery. Gene Expression 2:81-91.

90. Weintraub, S. J., and D. C. Dean. 1992. Interaction of a common factor with ATF, Sp1 or TATAA promoter elements is required for these sequences to mediate transactivation by the adenoviral oncogene E1A. Mol. Cell. Biol. 12:512-517.

91. Wen, P., N. Crawford, and J. Locker. 1993. A promoter-linked coupling region required for stimulation of $\alpha$-fetoprotein transcription by distant enhancers. Nucleic Acids Res. 21:19111918.

92. Wiley, S. R., R. J. Kraus, and J. E. Mertz. 1992. Functional binding of the "TATA" box binding component of transcription factor TFIID to the -30 region of TATA-less promoters. Proc. Natl. Acad. Sci. USA 89:5814-5818.

93. Wu, L., D. S. E. Rosser, M. G. Schmidt, and A. J. Berk. 1987. A TATA box implicated in E1A transcriptional activation of a simple adenovirus 2 promoter. Nature (London) 326:512-515.

94. Zawel, L., and D. Reinberg. 1993. Initiation of transcription by RNA polymerase II: a multi-step process. Prog. Nucleic Acid Res. 44:67-109.

95. Zenke, M., T. Grundström, H. Matthes, M. Wintzerith, C. Schatz, A. Wildeman, and P. Chambon. 1986. Multiple sequence motifs are involved in SV40 enhancer function. EMBO J. 5:387-397.

96. Zerler, B., R. J. Roberts, M. B. Mathews, and E. Moran. 1987. Separate functional domains of the adenovirus E1A gene are involved in regulation of host cell cycle products. Mol. Cell. Biol. 7:821-829. 